\title{
Can Quantitative Research Solve Social Problems? Pragmatism and the Ethics of Social Research
}

\author{
Thomas C. Powell ${ }^{1}$
}

Received: 21 December 2017 / Accepted: 23 May 2019 / Published online: 13 June 2019

(c) The Author(s) 2019

\begin{abstract}
Journal of Business Ethics recently published a critique of ethical practices in quantitative research by Zyphur and Pierides (J Bus Ethics 143:1-16, 2017). The authors argued that quantitative research prevents researchers from addressing urgent problems facing humanity today, such as poverty, racial inequality, and climate change. I offer comments and observations on the authors' critique. I agree with the authors in many areas of philosophy, ethics, and social research, while making suggestions for clarification and development. Interpreting the paper through the pragmatism of William James, I suggest that the authors' arguments are unlikely to change attitudes in traditional quantitative research, though they may point the way to a new worldview, or Jamesian "sub-world," in social research.
\end{abstract}

Keywords Quantitative research · Ethics · Pragmatism

\section{Introduction}

I was invited by the editors of this journal to comment on an article called "Is Quantitative Research Ethical? Tools for Ethically Practicing, Evaluating, and Using Quantitative Research" (Zyphur and Pierides 2017). The topic of the article is important and of great intrinsic interest to me, so I am pleased to offer this commentary. As will become clear, I agree with much of what the authors wrote, and with their overall philosophical orientation. The authors presented a compelling critique of traditional approaches to quantitative research $(\mathrm{QR})$ in the social sciences, offering an ethical orientation for organizational research and providing helpful examples of ethical approaches to $\mathrm{QR}$ in management studies.

Of course, agreement makes uninteresting commentary and it is pointless to repeat the authors' arguments and agree with them. What I have done instead is to play the devil's advocate, selecting a few key points from the paper and evaluating them from the perspective of a traditional $\mathrm{QR}$ practitioner. For example, the authors argued that traditional approaches to QR are not objective but value-laden. I agree

Thomas C. Powell

thomas.powell@sbs.ox.ac.uk

1 Said Business School, University of Oxford, Park End Street, Oxford OX1 1HP, UK with this (see Powell 2001a), but I evaluate whether the authors' proposals alleviate this problem or make it worse. The authors argued that quantitative researchers should do their part to solve human problems. I agree with this (see Powell 2014a), but I consider whether the problems they discussed were caused by quantitative methods, and whether it is reasonable to expect any research method to solve them. The authors endorsed a pragmatist epistemology as against foundationalist or "correspondence" epistemologies. I agree with this (see Powell 2001b, 2002, 2003, 2014b), but I review the origins of pragmatist philosophy and consider whether pragmatism can legitimately be used to justify the social agendas of academic researchers.

My overall theme is that we should be careful what we wish for. If all social research is value-laden, then we should be wary of privileging the values of a particular community, including the community of socially minded elites working in universities, or of academic journal editors who aspire to make social impacts in the world. Many of us want to solve human problems but we should also examine ourselves, asking if we are the right people for the job, working in the right places, carrying the right tools. The authors' pragmatic philosophy can help explain the nature of research practices, but it may not be the best platform for choosing between the competing values of academic researchers.

In the next section, I briefly summarize the argument in Zyphur and Pierides (2017) and provide overall comments. 
After that, I explore a few of the authors' arguments in detail, considering their wider implications for social research. I conclude with a discussion of pragmatism in social research, examining the pragmatism of William James and its consequences for ethics in social research.

\section{Commentary}

\section{Overview of Zyphur and Pierides (2017)}

Zyphur and Pierides (2017) offered an ethical critique of traditional quantitative research $(\mathrm{QR})$ in the social sciences. The authors challenged the philosophical foundations of traditional QR, such as its rationalist-materialist ontology and presumed scientific "objectivity." They also challenged specific methods and practices in social research, including "best practices" in research design, sampling, measurement, hypothesis testing and data analysis.

The authors' core message was that traditional QR practices are not objective but value-laden. Implicitly or otherwise, traditional QR takes an ethical position that impedes research that might address the real problems facing humankind today, such as racial inequality, poverty, corruption, and climate change. The authors did not reject $\mathrm{QR}$ as an enterprise, but criticized the assumption that standard QR "best practices" are objective and value-free. The authors called for a new "built for purpose" approach, in which researchers make their ethical purposes clear at the start, adapting research designs and analytical methods to those purposes.

The authors criticized traditional assumptions of "representation," "correspondence," and "probabilistic inference." In traditional QR, researchers begin by defining theoretical constructs or variables that purportedly represent tangible or intangible objects in the real world. QR practitioners assume that these labels correspond to things in the external world with a degree of one-to-one accuracy; and they propose correlational or causal relations, which presumably correspond with how these objects relate in the real world. These relations are then tested by drawing samples which presumably correspond to larger populations. To establish the correspondence of sample results to populations, researchers use probabilistic inference, which they represent by statistical artefacts such as regression coefficients, confidence intervals and $p$-values.

The authors argued that the assumptions of traditional QR - that labels correspond to things; that hypothesized relations correspond to actual relations; that samples correspond to populations; that probabilistic inference allows valid inductions-are open to philosophical and methodological objections across the board, some of which the authors discussed in the paper. More to the point, however, traditional QR methods smuggle hidden values into the research process, dictating which research questions can be asked, how constructs can be measured, and how data can be gathered and analysed. According to the authors, these values, operating under a cover of scientific respectability, impede social researchers who would use QR to improve the human condition.

As an alternative to traditional $\mathrm{QR}$, the authors proposed a "built for purpose" approach, in which researchers do not mimic traditional QR, but develop QR practices capable of addressing real human problems in the world. Instead of starting with representations and correspondences, researchers should start with a clear ethical purpose-for example, to combat corporate corruption or to eliminate racial discrimination. Instead of focusing on concept validity, construct validity, and other correspondences, researchers should maximize "relational validity"- that is, the "mutual fitness" of research designs, analytical methods, and ethical purposes. According to the authors, "relational validity offers a novel response to the centuries old problem of induction." (p. 12).

The authors argued that a "built for purpose" approach requires new perspectives and research practices, which they called "orientations" and "ways of doing." The new "orientations" require researchers to begin by asking, "Who is the research for?" "What is it trying to achieve?" and "How will it improve the human condition?" The new "ways of doing" require researchers to adapt research methods-measurement, sampling, data analysis, and causal inferences- to ethical purposes. In proposing this approach, the authors aimed to dispel traditional QR's fixation on scientific objectivity by "putting QR to work for other purposes that are of greater concern-inequality, global warming, or corruption." (p. 2).

\section{Comments on Zyphur and Pierides (2017)}

To evaluate the paper on its own terms, I want to say what I think the authors were trying to do, and not trying to do. In particular, I do not think the authors were making an exhaustive technical critique of quantitative methods in social research. The authors criticized certain tendencies in QR practice-such as data-mining for low $p$-values (" $p$-hacking"), and focusing on averages in regression analysis-but seemed less concerned with statistical technique than with the broader goal of "disrupting the universality" of scientific method. Their main recommendations - that researchers should focus on human problems, "built for purpose" research designs, and the "mutual fitness" of methods and purposes - could be applied equally to quantitative or qualitative research. If the authors had intended the paper as a technical deconstruction of QR in the social sciences, much more could have been said, and indeed has been said by other authors (e.g. Gelman 2015; Schwab et al. 2011; Simmons et al. 2011; Vul et al. 2009). 
But the authors focused on a different point; namely, that traditional QR practices impede research on social problems even when these practices are used as they were intended. Researchers should avoid obvious errors in statistical inference, such as inferring causation from correlation. But if the real problem in $\mathrm{QR}$ is unthinking obedience to the orthodoxies of scientific method, the issues are behavioural rather than statistical. For example, replicability and generalizability are sound QR principles, but they incentivize research on repeatable problems while neglecting specific or non-replicable contexts; and representative sampling improves probabilistic inference, but many human problems involve minorities facing unique hardships. Hence the authors focused less on QR technique than on the need for new "orientations" and "ways of doing" in the choice and implementation of QR methods.

This approach places the authors in a tradition reminiscent of C. Wright Mills in The Sociological Imagination (1959). Mills criticized the "abstracted empiricism" of quantitative sociology in mid-20th century North America; that is, the trend of importing assumptions from the natural sciences, defining social constructs as if they were physical objects, and using statistical methods to define problems rather than the other way around. Like Zyphur and Pierides, Mills argued that social researchers should put the scientific method in the service of research problems: "Controversy over different views of 'methodology' and 'theory' is properly carried on in close and continuous relation with substantive problems." (Mills 1959, p. 83) Mills was concerned less with statistical methods than with the philosophies lurking beneath the supposed "objectivity" of quantitative social research:

As a matter of practice, abstracted empiricists often seem more concerned with the... Scientific Method. Methodology, in short, seems to determine the problems. And this, after all, is only to be expected. The Scientific Method that is projected here did not grow out of, and is not a generalization of, what are generally and correctly taken to be the classic lines of social science work. It has been largely drawn, with expedient modifications, from one philosophy of natural science. (Mills 1959, pp. 39, 40)

The authors share not only Mills' scepticism of scientific method but also his philosophical pragmatism. It is important to recognize the authors' pragmatism and not to conflate it with ontologies aligned with nominalism, subjectivism, social constructionism, and postmodern social theory. The authors sympathize with these views, but to classify their position as "subjectivism" or "social constructionism" would be to misunderstand what they are saying. When the authors use a term like "correspondence," they are not making a vague reference to similarity, but invoking the terminology of the pragmatist philosophy of science. Pragmatism anticipated many of the philosophical moves that would later characterize postmodern social theory, but the two approaches have different origins, and different consequences for social research.

Although the authors explained their pragmatism in an earlier paper (Zyphur et al. 2016), they might have done more in the current paper to guide readers through their philosophical position, linking pragmatism with their critique of traditional QR and recommendations for future QR practice. As it stands, the paper seems to blend non-pragmatist and pragmatist ideas together in a kind of free-floating subjectivist relativism that may strike some readers as confusing or unhelpful. For example, in explaining their approach, the authors used abstract language that is hard to place in any philosophical tradition:

To begin, we put forth two infinitely long and intersecting dimensions of $\mathrm{QR}$ practice that we call orientations and ways of doing, which connect purposes to QR practice. Instead of being 'foundations' or somehow fundamental in a representation correspondence sense, each category and its contents are akin to idioms or axiomatic lists that tend toward infinity because they can be populated indefinitely, limited only by the creativity of those who adopt them. They may also be orthogonal, indicating that each orientation can, at least in theory, be combined with any way of doing $\mathrm{QR}$ in order to achieve a given purpose. In what follows, we describe these dimensions, beginning to populate the lists that may constitute each dimension while illustrating the fruitfulness of combinations that emerge. However, there are two caveats to mentioned upfront which, if ignored, undermine our broader recommendations. (p. 4)

Due in part to the paper's lack of clarity, both in language and narrative structure, a skeptical reader might argue that the authors have left their recommendations open to ethical misinterpretation, even by those who want to put them into practice. For example, a reader might interpret the authors' "built for purpose" method roughly as follows: (1) Identify a serious social problem (poverty, racial inequality, climate change, etc.); (2) Choose a desired outcome (elimination of poverty, racial equality, climate stabilization, etc.); (3) Design a quantitative study that demonstrates the severity of the problem; (4) Use the quantitative results to campaign for social change that solves the problem.

This is an oversimplification of the authors' advice, but a traditional QR practitioner might argue that the method ignores the crucial distinction between ethical outcomes and ethical processes. The received scientific method has many faults, but it recognizes, in principle, that scientists should not choose their desired outcomes or contrive their 
research processes to achieve those outcomes. Admittedly, scientists have abused scientific method in exactly this way, but the whole point of scientific method is to neutralize researchers' preferences. Without a relatively objective process, researchers will choose the outcomes they want and manipulate research processes to achieve them. These manipulations may produce social changes, and some of the changes may be socially desirable-but this is not an ethical process unless we believe that "the ends justify the means" (consequentialist ethics) or that "bad people achieve their goals this way, so good people must do it too" (compensatory ethics). Either way, achieving social purposes comes at a high ethical price.

Similarly, a critic might stand behind the Rawlsian "veil of ignorance" (Rawls 1971) and ask: If we wanted accurate and reliable research on a social problem, would we prefer a team of researchers bound to a fixed research process they believe is ethical, or a team of researchers bound to a fixed social outcome they believe is ethical? Either team might have false beliefs, so the research process might actually be unethical, or the social outcome might be unethical. The problem is that a research team bound to a fixed outcome will reach the same conclusions whether the outcome is ethical or not, whereas a team that follows a fixed process has a chance of reaching new conclusions; and, if its process is ethical, of reaching conclusions independent of its own preferences. A reasonable person behind the Rawlsian veil might prefer a process capable of producing new or unbiased results, even if the process was imperfectly implemented.

Traditional quantitative researchers might also challenge the authors' assumption that researchers who practice their methods are the ones who should define the world's problems and decide which ideas get published. How do we know their values are trustworthy? If an ethical problem exists with scientific method, should we relocate our trust from the scientific community to a sub-community of socially minded university professors, journal editors and government funding agencies? Does this sub-community have a shared and coherent view of social ethics and human purposes - and if not, by what process will they define and prioritize social outcomes? What would stop an ambitious social researcher with political connections and a social media profile from hijacking the method to perpetrate mass social harm?

The authors rightly point out that traditional QR is not value-free, nor is scientific method in general. Scientists often allow quantitative methods to dictate research problems, and they have perverse incentives to find publishable results in their data. When QR is driven by methods indifferent to human purposes, it crowds out research that might address large-scale human problems. All of this is true. On the other hand, the authors' claim that traditional QR is "ethics-laden" relies on the charge that it "produces an orientation toward "facts' rather than "values." (p. 3).
Therefore, the authors need to show how a commitment to facts undermines the solving of human problems, and how a commitment to values removes the ethical biases of traditional methods. Unfortunately the paper does not provide the needed clarity:

By separating facts from values, facts appear to be unrelated to ethics; and with a focus on facts, ethics appear irrelevant for QR validity... New understandings of validity are needed to address the ways that QR is an ethical act and ethically consequential. This ethicality may be unrelated to representation or correspondence, such as if QR is meant to produce images of society that change the way people think and act - an enactment of a reality that did not yet exist to be merely 'represented'... (p. 7)

Many researchers, qualitative and quantitative alike, may disagree with the authors on the fundamental nature and purpose of social research. For example, the authors implicated traditional QR in the global financial crisis (p. 10 ), but many traditional researchers would reject any suggestion that the financial crisis can be laid at the doorstep of a research method-why not qualitative methods?-or that a research method can solve the world's problems. Traditional QR practitioners would acknowledge that "Determine the nature and extent of human poverty" is a QR problem; but they would not acknowledge that "Eliminate human poverty" is a QR problem. In their worldview, it is a human problem, a social problem, an economic problem, a political problem, a gender problem, a racial problem, and many other kinds of problem. QR can help us understand what is going on in the domain of human poverty, and QR analysis provides input to policy-makers. But this does not prove that researchers should stop using "best practices," but merely begs the question of whether traditional QR or "built for purpose" QR is the better method for understanding what is going on.

QR practitioners might also question the authors' logical consistency in rejecting assumptions like "representation" and "correspondence." Presumably, when the authors made statements about traditional QR-for example, that QR includes hypothesis testing and regression analysisthey were affirming that their sentences represented something, and that their ideas corresponded to something beyond words on a page. When the authors wrote "QR is often done in terms of representation and correspondence (Zyphur et al. 2016)" (p. 2), they affirmed that this proposition, and the term "Zyphur et al. (2016)," corresponded to things and persons that possessed a reality independent of the words, even if that reality was a social construction rather than an objective material object. In other words, the authors seemed to be using representation and correspondence to critique representation and correspondence. 
I think QR researchers will be especially interested in the illustrations of exemplary QR provided by the authors. Without critiquing the papers individually, the examples show that the search for better QR methods is fraught with pitfalls. Regardless of QR methods, social research is a human process concerned with human subjects. It is not obvious that researchers who follow the QR method of Zyphur and Pierides are behaving more ethically than researchers who follow traditional QR, even when they are researching worthy causes. The choice is not between ethical and unethical QR, but among a range of imperfect quantitative methods, each inviting its own forms of human error. Along with the authors, I hope that QR can make contributions to solving human problems; but I also believe that if we did not have something like traditional QR, we would have to invent it. Whatever its flaws, the question is not whether scientific method eliminates human error, but whether, among the imperfect alternatives available to us, it gives us the best explanations for what is going on in the world.

This is why we must be careful what we wish for. Humanity is confronted with many problems, and social researchers need to find a way to do their part. Whatever objections can be raised against the paper, I endorse what the authors are trying to achieve. But removing or reforming traditional QR will not solve the problems of the human condition because these problems are not caused by a research method. The problems of the human condition are caused by people, and shifting responsibility from one group of researchers to another will not improve the human condition. We should use QR to address human problems, while bearing in mind that the authors' method confers power to solve the world's problems on fallible people and institutions-academic elites, journal editors, and the governments, corporations and philanthropic agencies that fund social research - which have vested interests of their own, and are, to a significant degree, responsible for the problems we are trying to solve.

\section{William James and Ethics in Management Research}

I have written elsewhere about pragmatism and its relevance for organizational research Powell 2001a, 2002, 2014a). In this section, I want to show how pragmatism, or a version of it, relates to the ethical issues raised by Zyphur and Pierides. In particular, I want to examine the pragmatism of William James and its consequences for ethics in management research.

In doing this I am prompted by statements in Zyphur and Pierides (2017) and its predecessor (Zyphur et al. 2016), such as:
'Best practices'... may be useful for the purpose of standardizing QR, but this... distracts from the task of putting QR to work for other purposes. (Zyphur and Pierides 2017, p. 14)

Inductive inference means actively working to enact research purposes, making research 'true' by helping it to shape the world. (Zyphur and Pierides 2017, p. 13) Many pragmatists propose that organizing practical action is the point of thinking and speaking... (Zyphur et al. 2016, p. 478)

Instead of having to gather large samples to avoid statistical errors of inference, researchers would be better off trying to guard against actions that have unhelpful consequences. (Zyphur et al. 2016, p. 478)

I agree with the authors' turn to pragmatism and their rejection of conventional philosophical foundations. As a philosophy of science, pragmatism is concerned with human purposes, and the authors are right to cite pragmatism in supporting ethics in social research. However I hope that readers will not misconstrue pragmatism as a literal invitation to reject QR "best practices" while "putting QR to work for other purposes." Philosophical pragmatism argues that most statements about truth and being (epistemology and ontology) can be resolved into statements about things people actually do, or might do. They do not resolve, however, into statements about what people should do. To explain why pragmatists make this distinction, and to show its consequences for the method proposed by Zyphur and Pierides, requires a brief digression on the origins of William James's pragmatism.

William James developed his pragmatist philosophy over many years, exploring its consequences for psychology, epistemology, ontology and philosophy of science (e.g., James 1890a, 1902, 1907). In the two-volume Principles of Psychology (1890b), James linked psychology with philosophy through the concept of belief. He asked: What happens in the consciousness of a subjectively experiencing human being when confronted with a statement of fact, or proposition? What feelings are evoked? How does a person translate the words of a proposition into the state of consciousness we call "belief"?

James argued that belief occurs when a proposition evokes marked feelings of subjective rightness, like a puzzle piece fitting into place. Instead of discomfort or agitation, a proposition evokes a sense of cognitive and emotional harmony, producing a warm psychological glow of mental assent. In Jamesian psychology, belief $i s$ the warm psychological glow of mental assent. People justify their beliefs using underlying reasons or causes, such as sense data, logic, intuition, authority, persuasion, or common sense. But belief is a feeling, not a fact; and the belief that a belief is a fact and not a feeling, is also a feeling. In Jamesian psychology, 
a justification only counts as belief when it evokes the feeling, or psychological "yes" signal, that provides the glow of subjective rightness.

James's theory of belief formed the psychological foundation for his pragmatism. An object becomes real for people when they believe in its existence; and a proposition becomes true for people when they believe in its truth. Scientific propositions become true for scientists when scientists believe in their truth. This does not mean that scientific propositions are arbitrary, or do not correspond with sense observations shared with other people. In Jamesian ontology, people have no direct access to metaphysical "truths" or "realities," so their beliefs rely on sense data, logic, intuition, and other forms of justification. Indeed, other peoples' beliefs are themselves unobservable, so we infer them from what people say and do. When we affirm that something is "true" for other people, what we mean is that we have observed people saying and doing things that make us believe that they believe that the thing is true. Human behaviour-what people say and do, including ourselvescomprises the whole of the evidence.

Despite his interest in the experiencing person, James did not see pragmatism as justifying a relativist or subjectivist social science, any more than it justified a positivist or objectivist one. James began as a physiologist, building his psychological theories on experimental physiology and the functional anatomy of the human brain; and his pragmatism did not deny the existence of the external world, the laws of propositional logic, or the validity of scientific method. James observed reality through the medium of human consciousness, which he held to speak for itself and not for things outside itself. James did not deny the existence of an external world, but saw the external world as becoming manifest through the meanings conferred on it in the perceptions and interpretations of human beings.

In Jamesian pragmatism, people adopt beliefs in order to solve problems in human consciousness, and these problems are infinitely varied. James did not propose pragmatism as a form of prescriptive advice to scientists, urging them to focus on final purposes instead of processes, or to "be practical" instead of thinking abstractly. The problems of poets and metaphysicians are not "practical" compared to the problems of engineers and airline pilots, but pragmatism does not urge poets to become more practical. Pragmatism is a descriptive theory of human ontology and epistemology which holds that people derive their ideas of truth and reality not from comparisons between propositions and realities, but by solving problems that arise in human consciousness. The theory makes no claims about the degree of "practicality" of interests or problems people may or should have.

Beyond affirming the centrality of human experience for psychology and philosophy of science, James argued that any phenomenon in the domain of human consciousness can become a legitimate object of human inquiry. Whatever has meaning for an experiencing human being has ontological reality, and there are no greater or lesser realities. The beliefs we call "scientific," derived from theory and empirical observation, do not have higher ontological status, or "more reality," than other propositions in human consciousness, and hence no superior claim on truth. Everything that enters human consciousness has the same eligibility for inquiry, examination and analysis, whether derived from sense experience, reasoning, dreams, delusions, hallucinations, mythology, or religious faith.

James saw the natural sciences as domains of human inquiry concerned with aspects of human consciousness associated with the natural world. While recognizing the widespread human impacts of science, James regarded the scientific community as one of many "sub-worlds" of human inquiry (see James 1890b, p. 291). A Jamesian sub-world, like a Wittgensteinian "language game," denotes a community of inquiry with its own conventions, beliefs and vocabularies (on Wittgenstein's reliance on James's pragmatism, see Goodman 2002). By the conventions of the scientific sub-world, scientists follow a method of inquiry grounded in theory, quantification, measurement and experiment, while rejecting propositions grounded in private opinion or groundless speculation. James acknowledged the efficacy and significance of science, since its problems very often affect non-scientists, and solving them makes life better (or worse) for many people. At the same time, James affirmed that scientific problem-solving conventions do not give scientists superior access to extra-experiential realities, but function in human consciousness like other conventions.

James's philosophy allowed for great pluralism among the sub-worlds of human inquiry; for example, there are subworlds of myth, literature, art and religion, each with its own conventions, beliefs, and vocabularies. James argued that these sub-worlds produced beliefs that were no less real or true, within their own conventions, than the beliefs of natural scientists - and that it was futile to judge the beliefs of one sub-world by the conventions of another: to the poet, a scientific discovery may seem misguided; or to a scientist, a religious inspiration may seem superstitious. Participants negotiate conventions within their own sub-worlds, but pragmatism does not make value judgments about the comparative legitimacy of sub-worlds. As in James's The Varieties of Religious Experience (1902), any phenomenon that appears in human consciousness is fruitful subject matter for human inquiry.

And this is where ethics comes in. Pragmatists do not hold that truth is relative or a matter of preference. Each sub-world of inquiry follows its own problemsolving conventions, and these conventions become relatively hardened, even as they continue to evolve. Within the sub-world of science, truth is not groundless but 
evidence-based, and to pretend otherwise is not merely to get it wrong, but to behave unethically. Scientists can debate the kinds of evidence that bear on a particular question, but they cannot debate whether evidence bears on scientific questions. Theologians can debate whether God is known by faith, revelation, or church tradition, but they cannot debate whether God is relevant to theology. Outside claimants who deny the conventions of a subworld, unlike insiders disputing how those conventions are applied, are perceived not merely as mistaken, but as immoral, ignorant or both. Disputes within a sub-world of practice can solve problems for participants, but disputes across sub-worlds tend to devolve into name-calling and ethical recrimination.

From a Jamesian pragmatist perspective, the debate initiated by Zyphur and Pierides is a dispute across sub-worlds rather than a conversation that can be progressed within the sub-world of QR practice. Quantitative social research is a legitimate sub-world of practice, and like the proposals by C. Wright Mills a half-century earlier, the authors' proposals are unlikely to alter or deter that sub-world. From the perspective of the traditional QR sub-world, the debate initiated by the authors-dropping QR best practices and using QR to achieve researchers' social aspirations-is not so much a challenge to $\mathrm{QR}$ practice as a kind of category mistake. The authors' paper is not written in the language of quantitative researchers, it does not acknowledge their legitimacy, it does not anticipate or address their potential responses, and it proposes to overthrow the standards of their community without discussing the consequences of abandoning those standards. The authors seem to inhabit a different sub-world altogether, and the two sub-worlds do not have very much to say to each other.

I believe this is a good thing. If traditional $Q R$ is a legitimate sub-world of practice, so is the sub-world proposed by the authors. I can imagine a sub-world in which people put QR in the service of solving human problems, with its own conventions, beliefs and vocabularies. This sub-world cannot replace traditional QR or operate within it, but requires an independent code of practice and community of participants. To build this community within the conventions of traditional QR would constrain and diminish both traditional QR and what the authors are trying to accomplish. The authors have started the conversation by articulating a set of principles for purpose-driven QR. Perhaps now they can define the social and intellectual agenda for this community, and build the human and institutional infrastructure required for its growth and development. I support what they are trying to do and I hope they succeed.
Funding The author received no funding to support this research.

\section{Compliance with Ethical Standards}

Conflict of interest The author declares having no conflict of interest in this research.

Research Involving in Human and Animal Rights The author declares that this article does not contain any studies with human participants or animals performed by the author.

Open Access This article is distributed under the terms of the Creative Commons Attribution 4.0 International License (http://creativeco mmons.org/licenses/by/4.0/), which permits unrestricted use, distribution, and reproduction in any medium, provided you give appropriate credit to the original author(s) and the source, provide a link to the Creative Commons license, and indicate if changes were made.

\section{References}

Gelman, A. (2015). The connection between varying treatment effects and the crisis of unreplicable research: A Bayesian perspective. Journal of Management, 41(2), 632-643.

Goodman, R. B. (2002). Wittgenstein and William James. Cambridge UK: Cambridge University Press.

James, W. (1890a). The principles of psychology (Vol. I). New York: Henry Holt and Company.

James, W. (1890b). The principles of psychology (Vol. II). New York: Henry Holt and Company.

James, W. (1902). The varieties of religious experience: A study in human nature. London: Longmans, Green and Co.

James, W. (1907). Pragmatism: A new word for some old ways of thinking. London: Longmans, Green and Co.

Mills, C. Wright. (1959). The sociological imagination. New York: Oxford University Press.

Powell, T. C. (2001a). Competitive advantage: Logical and philosophical considerations. Strategic Management Journal, 22(9), 875-888.

Powell, T. C. (2001b). Fallibilism and organizational research: The third epistemology. Journal of Management Research, 4, 201-219.

Powell, T. C. (2002). The philosophy of strategy. Strategic Management Journal, 23(9), 873-880.

Powell, T. C. (2003). Strategy without ontology. Strategic Management Journal, 24(3), 285-291.

Powell, T. C. (2014a). Strategic management and the person. Strategic Organization, 12(3), 200-207.

Powell, T. C. (2014b). William James. In Jenny Helin, Tor Hernes, Daniel Hjorth, \& Robin Holt (Eds.), The Oxford handbook of process philosophy and organization studies (pp. 166-184). Oxford: Oxford University Press.

Rawls, J. (1971). A theory of justice. Cambridge MA: Belknap.

Schwab, A., Abrahamson, E., Starbuck, W. H., \& Fidler, F. (2011). Researchers should make thoughtful assessments instead of nullhypothesis significance tests. Organization Science, 22, 1105-1120.

Simmons, J., Nelson, L., \& Simonsohn, U. (2011). False-positive psychology: Undisclosed flexibility in data collection and analysis allow presenting anything as significant. Psychological Science, 22, 1359-1366.

Vul, E., Harris, C., Winkielman, P., \& Pashler, H. (2009). Puzzlingly high correlations in fMRI studies of emotion, personality, and social cognition. Perspectives on Psychological Science, 4(3), 274-290. 
Zyphur, M. J., \& Pierides, D. C. (2017). Is quantitative research ethical? Tools for ethically practicing, evaluating, and using quantitative research. Journal of Business Ethics, 143, 1-16.

Zyphur, M. J., Pierides, D. C., \& Roffe, J. (2016). Measurement and statistics in 'organization science': Philosophical, sociological, and historical perspectives. In R. Mir, H. Willmott, \& M. Greenwood (Eds.), The Routledge companion to philosophy in organization studies (pp. 474-482). Abingdon: Routledge.
Publisher's Note Springer Nature remains neutral with regard to jurisdictional claims in published maps and institutional affiliations. 